\title{
Rapid Separation of Five Cyclosporin Analogs by Supercritical Fluid Chromatography
}

\author{
Yuefei Shao, Chunlei Wang, Atsu Apedo, Oliver Mcconnell \\ Bioanalytical and Discovery Analytical Sciences, Research \& Development, Bristol-Myers Squibb, Princeton, \\ New Jersey, USA \\ Email: chunlei.wang@bms.com
}

Received 30 March 2016; accepted 19 June 2016; published 22 June 2016

Copyright $(2016$ by authors and Scientific Research Publishing Inc.

This work is licensed under the Creative Commons Attribution International License (CC BY). http://creativecommons.org/licenses/by/4.0/

c) (7) Open Access

\begin{abstract}
Recently there has been a resurgence of interest in cyclic peptides due to their therapeutic advantages in terms of potency, permeability, proteolytic stability, and unique selectivity relative to traditional smaller drug molecules. Cyclosporin is a family of cyclic peptides widely used as autoimmune suppression agents. Cyclosporin analogs consist of eleven amino acids with the main difference lying at the side chain of its amino acid residues. In this study, a single step separation method was developed utilizing Supercritical Fluid Chromatography (SFC) to resolve five naturally occurring cyclosporin analogs (Cyclosporin A, B, C, D, and H) on a bare silica-packed column. The optimized method involved use of ethanol-modified carbon dioxide as mobile phase on a bare silica column at $80^{\circ} \mathrm{C}$ and $\mathrm{UV}$ detection at $220 \mathrm{~nm}$. Although column temperature and back pressure generally had insignificant effect on SFC separation, it was found in our study that increasing temperature and pressure greatly improved peak shape and resolution.
\end{abstract}

\section{Keywords}

Cyclic Peptide, Cyclosporin, Supercritical Fluid Chromatography

\section{Introduction}

Peptide therapeutics has played an important role in the pharmaceutical industry. In general, linear peptides have the advantages of potency, selectivity and less toxicity compared with small-molecule therapeutics [1]. The major drawback of linear peptides is their inherently poor proteolytic stability. On the other hand, many cyclic peptides have relatively rigid chemical structures and constrained conformations, and have demonstrated signifi-

How to cite this paper: Shao, Y.F., Wang, C.L., Apedo, A. and Mcconnell, O. (2016) Rapid Separation of Five Cyclosporin Analogs by Supercritical Fluid Chromatography. Journal of Analytical Sciences, Methods and Instrumentation, 6, 23-32. http://dx.doi.org/10.4236/jasmi.2016.62004 
cantly improved pharmacokinetic profiles, in vivo stability and bioavailability comparing to their linear counterparts [2]. Consequently, cyclic peptides have reemerged as a new therapeutic modality in drug discovery [3]. Many of the discovery efforts have focused on natural or synthetic cyclic peptides with ten or more residues that feature natural amino acids or synthetic analogs [4]-[6].

One of the most prominent cyclic peptide drugs is Cyclosporin (Cs), a potent immunosuppressive agent that has been widely used in organ transplantation to prevent immune rejection and viral infection as it allows selective immunoregulation of $\mathrm{T}$ cells. The Cyclosporin family contains a number of cyclic undecapeptide analogs with eleven amino acid residues including an unusual amino acid N-methyl butenyl-methyl-L-threonine (mBMT). Structurally the Cyclosporin analogs differ at the side chain of amino acid residues. Cyclosporin A (CsA) is the most commonly used analog and was first isolated from soil fungus by multi-step extractions [7]. Reversed phase HPLC has been widely used to separate CsA and CsC [8] [9]. Due to structural similarity, separation of multiple Cyclosporin analogs was complicated and involved multiple chromatographic procedures. Lensmeyer reported separation of CsA and its nine metabolites by means of multiple HPLC steps with sequential use of different columns (cyano, octyl and silica) and a mixture of water/acetonitrile/tetrahydrofuran with acetic acid/n-butylamine additives as mobile phases [10].

The low viscosity and high diffusivity features of supercritical fluid chromatography (SFC) make it a superior separation technique. SFC has been widely recognized as an especially powerful tool for achiral separation of structurally similar analogs, and chiral separation of stereoisomers. For linear peptides, although most literature reports involved application of Reversed Phase HPLC methodology, it had been reported that SFC was used to separate multiple linear peptide analogs, such as separation of pentadecapeptides of gramicidin analogs on a poly(styrene-divinylbenzene) column with methanol-modified $\mathrm{CO}_{2}$ mobile phase [11], and separation of pairs of dodecapeptide isomers on a bare silica packed column with water/methanol as modifiers [12]. Zheng et al. reported separation of linear peptides up to 40 amino acid residues including angiotensin and urotensin by SFCMS on an ethylpyridine column using methanol with 5 - $13 \mathrm{mM}$ TFA as mobile phase modifier [13]. The authors claimed that the acidity of the mobile phase modifier was critical and the amount of TFA additive varied with different polypeptides. In terms of cyclic peptides separation by SFC, there were only a few literature reports and most of them involved CsA. Kalinoski reported one of the earliest SFC applications in analysis of Cyclosporin A, using a packed microbore C-18 column with methanol-modified $\mathrm{CO}_{2}$ mobile phase [14]. A preparative SFC method was reported to purify CsA from fermentation extract at industrial scale with a two-step SFC protocol using toluene/isopropanol-modified $\mathrm{CO}_{2}$ as mobile phase on bare silica columns [15]. However, simultaneous separation of multiple Cyclosporin analogs by one-step SFC has never been reported. The goal of our work was to develop an SFC method for rapid separation of five naturally occurring Cyclosporin analogs (Table 1) and to further study their chromatographic behavior.

\section{Experimental Section}

\subsection{Material}

General solvents for sample and mobile phase preparation were purchased from Aldrich (St. Louis, MO, USA) and were used without further purification. Cyclosporin A, B, and H were purchased from Santa Cruz Biotechnology Inc. (Dallas, TX, USA), Cyclosporin C was purchased from Enzo Life Sciences (Farmingdale, NY, USA). Cyclosporin D was purchased from Toronto Research Chemicals Inc. (Toronto, ON, Canada).

\subsection{SFC System}

The experiments were performed on an Agilent (Santa Clara, CA, USA) 1260 Infinity LC system equipped with

Table 1. Amino acid sequences of Cyclosporin analogs and cLogP values.

\begin{tabular}{cccc}
\hline Cs & Cyclic Peptide Sequence & cLogP \\
\hline A & Cyclo(mBMT-Abu-mGly-mLeu-mVal-mLeu-Ala-D-Ala-mLeu-mLeu-mVal) & 3.64 & \\
B & Cyclo(mBMT-Ala-mGly-mLeu-mVal-mLeu-Ala-D-Ala-mLeu-mLeu-mVal) \\
C & Cyclo(mBMT-Thr-mGly-mLeu-mVal-mLeu-Ala-D-Ala-mLeu-mLeu-mVal) & 3.12 & 3.01 \\
D & Cyclo(mBMT-Val-mGly-mLeu-mVal-mLeu-Ala-D-Ala-mLeu-mLeu-mVal) & 4.53 \\
H & Cyclo(mBMT-Abu-mGly-mLeu-mVal-mLeu-Ala-D-Ala-mLeu-mLeu-D-mVal) & 3.64 \\
\hline
\end{tabular}


an Infinity SFC module. Although many columns were evaluated, the column used primarily in this study was a Waters Corp (Milford, MA) Viridis Silica, with particle size of $5 \mu \mathrm{m}$, pore size of $100 \AA$, and dimension of $4.6 \times$ $250 \mathrm{~mm}$. The mobile phase in this study was an alcohol modified $\mathrm{CO}_{2}$ with a gradient of $5 \%-30 \%$ modifier at a total flow rate of $2 \mathrm{~mL} / \mathrm{min}$. Detection wavelength was $220 \mathrm{~nm}$. The column temperature was controlled by an Agilent 1260 Infinity column oven module and varied between $0^{\circ} \mathrm{C}$ to $80^{\circ} \mathrm{C}$. The backpressure was varied between 100 and 300 bar. The software for data collection and process was Openlab CDS Chemstation Rev. C.01.06.

\subsection{Cyclosporin Solution Preparation}

1) Individual Cyclosporin solution: A $2.5 \mathrm{mg} / \mathrm{mL}$ standard solution of each individual Cyclosporin analog was prepared in methanol, 2) Mixed Cyclosporin solution: An equal aliquot of each solution was taken and mixed together to get a mixed solution containing $0.5 \mathrm{mg} / \mathrm{mL}$ each of Cyclosporin $\mathrm{A}, \mathrm{B}, \mathrm{C}, \mathrm{D}, \mathrm{H}$. Individual solutions were injected for peak identification purpose.

\section{4. cLogP Calculation}

clogP calculations were performed with ChemAxon's MarvinView (version 6.3.1) whose algorithm is based on a modified version of the method of Viswanadhan, where the predicted partition coefficients are composed of the molecules' atomic increments [16]. The applied modifications include the redefinition of selected atom types to accommodate electron delocalization (in particular for carbon, nitrogen, and sulfur atoms).

\section{Results and Discussion}

\subsection{Effect of Stationary Phases}

This study focused initially on screening SFC columns with various pre-packed SFC stationary phases, including unbonded silica, and silica particles bonded or capped with pyridinyl, 2-ethylpyridinyl, diethylaminopropyl, glycopeptidyl, cyano and octadecyl groups. Methanol was used initially as the mobile phase modifier during column screening. Among all the stationary phases tested, the bare silica column showed the best separation potential for the Cyclosporin analogs (Figure 1). The directly exposed hydroxyl group on the silica surface was deemed important for the successful separation of the five analogs. To test out the scope and effect of the hydroxyl stationary phase, a Waters Torus diol column, with silica gel capped by diol through an ether linkage,

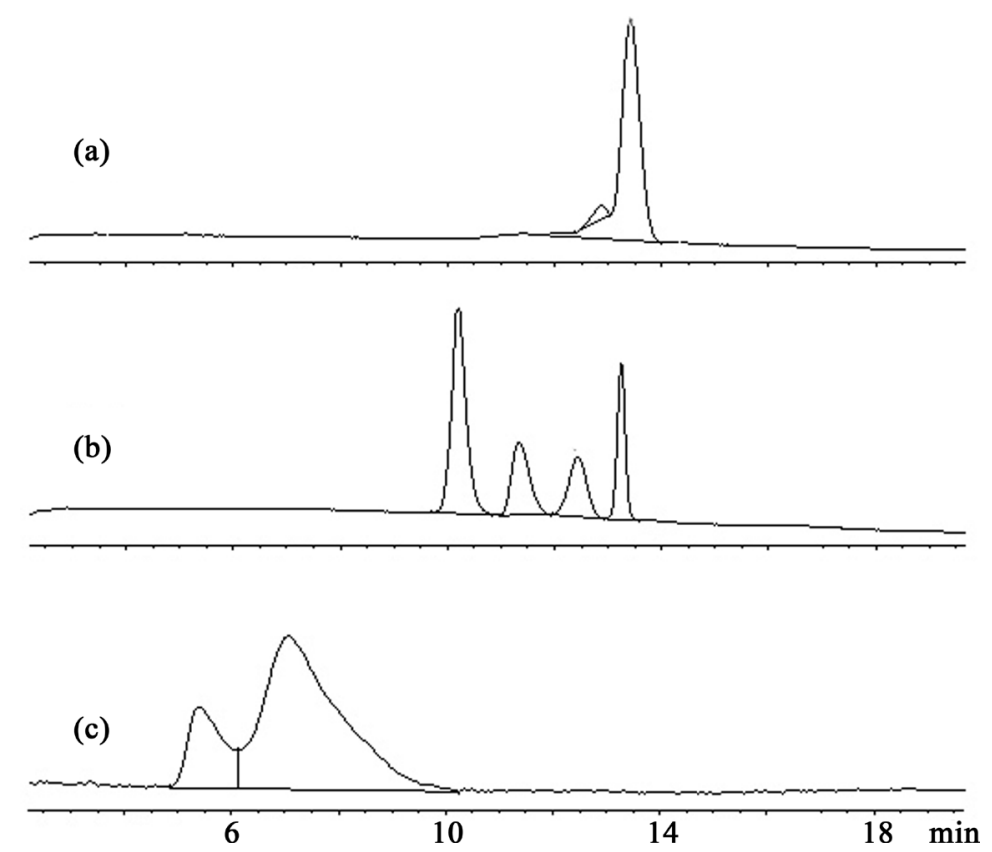

Figure 1. Stationary phase effect on SFC chromatograms of Cyclosporin analogs. Mobile phase: $\mathrm{CO}_{2}$ modified with EtOH at 5\% - 30\% gradient, $2 \mathrm{~mL} / \mathrm{min}, 40^{\circ} \mathrm{C}, 150$ bar. Column: (a) Pyridine, (b) Bare silica, (c) Chiralpak IC. 
was also tested. The diol column did not produce good separation although it had high density hydroxyl groups on the surface. SFC columns with amylose or cellulose based chiral stationary phases (Chiralcel OD, OJ, and Chiralpak AD, AS, IA, IB, IC, ID) were also screened and all Cyclosporin analogs were not separated.

\subsection{Effect of Mobile Phase Modifiers}

The initial attempt to separate the Cyclosporin mixture involved methanol as mobile phase modifier (mobile phase B). As shown in Figure 1, with a gradient of 5\% - 30\% B in 20 minutes, four peaks were observed on a bare silica column. In order to identify each peak, five individual Cyclosporin solutions containing each single analog were injected separately for retention time comparison and peak identification. It was found that Cyclosporin $\mathrm{H}$ and $\mathrm{D}$ were coeluted as the first peak followed by Cyclosporin $\mathrm{A}, \mathrm{B}$, and $\mathrm{C}$. When the mobile phase modifier was switched to ethanol, all the five Cyclosporin analogs were separated with an elution order of Cyclosporin H, D, A, B, C. When isopropanol was used as modifier, the five peaks showed longer retention times with broadened peak shape due to isopropanol's higher hydrophobicity and higher viscosity (Figure 2). When pure supercritical $\mathrm{CO}_{2}$ was used as mobile phase, none of the Cyclosporin analogs were eluted from the column.

The elution order for Cyclosporin D, A, B, C is consistent with their cLogP values (Table 1), since SFC is nominally considered a form of normal phase chromatography where analytes are eluted in order of decreasing hydrophobicity (Figure 3). However, CsH was eluted in the front of all the others though its cLogP value was calculated to be identical to CsA. Structurally, CsH contains an unusual D-N-methylvaline at the eleventh amino acid position while all the other four analogs contain an L-N-methylvaline at this position. Crystallization study by Brian Potter [17] has revealed that the change in chirality between CsA and CsH resulted in a major structural transformation from open beta-sheet in CsA to a highly convoluted conformation in CsH. This structural
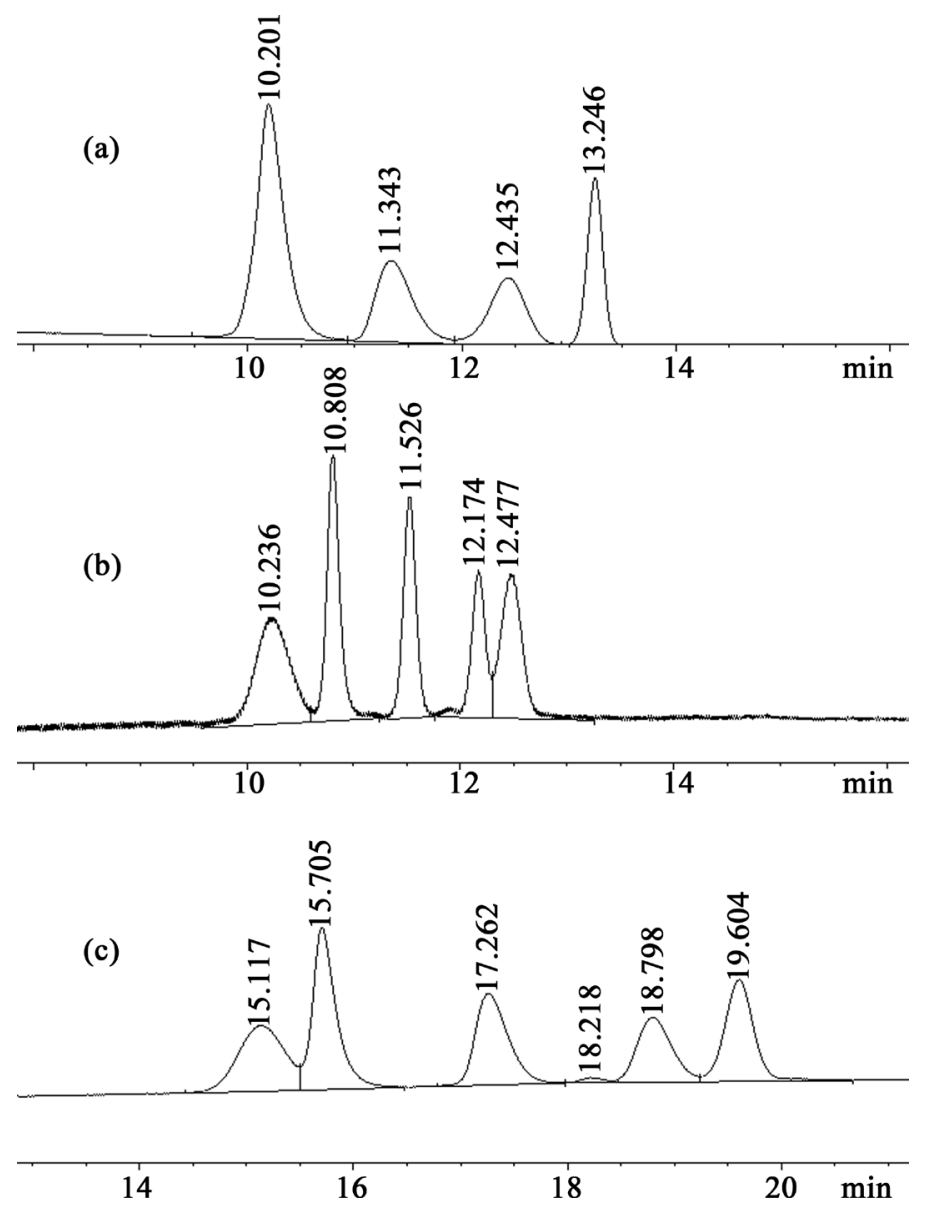

Figure 2. Mobile phase effect on SFC chromatograms of Cyclosporin analogs. Bare silica column, $40^{\circ} \mathrm{C}, 150 \mathrm{bar}, 5 \%-30 \%$ gradient. Mobile phase modifiers: (a) Methanol (b) Ethanol, (c) Isopropanol. Peak elution order: Cyclosporin H, D, A, B, C. 


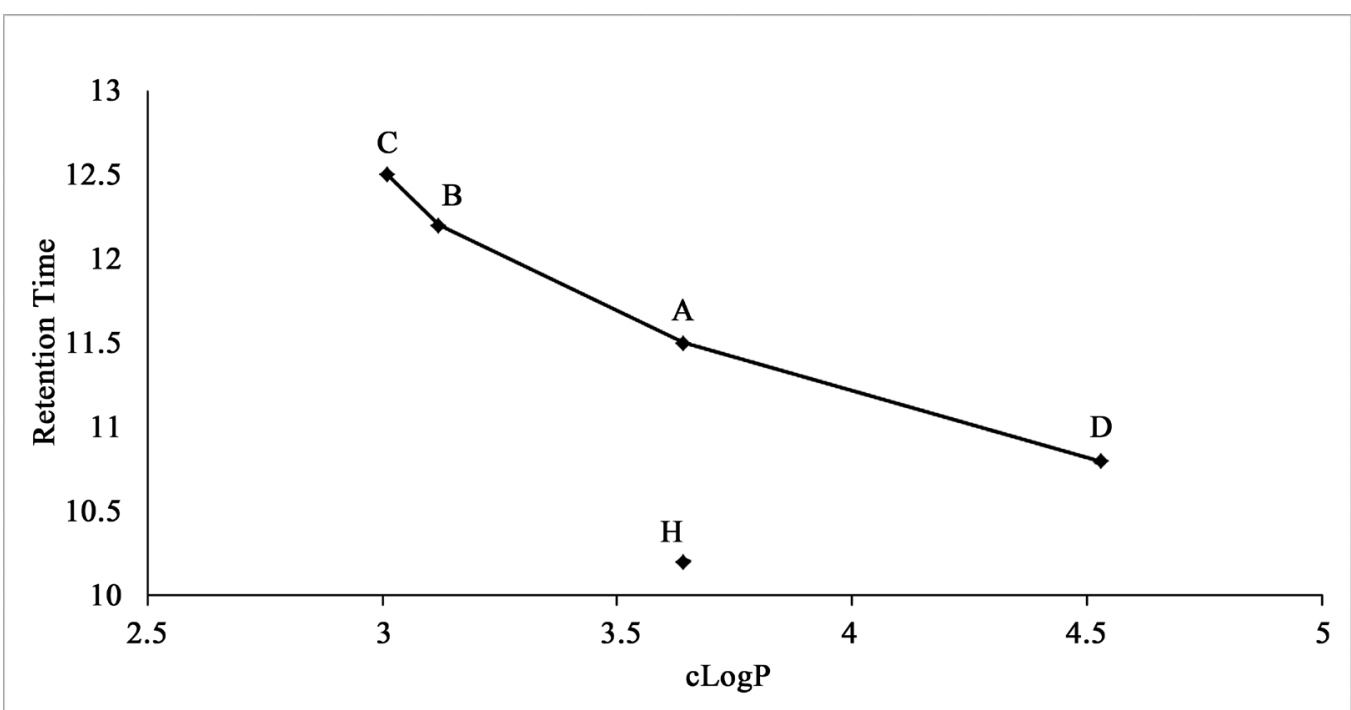

Figure 3. Retention time-cLogP relationship. Bare silica column, mobile phase: $\mathrm{CO}_{2}$ modified with EtOH at $5 \%$ - 30\% gradient, $2 \mathrm{~mL} / \mathrm{min}, 40^{\circ} \mathrm{C}, 150$ bar.

change further altered its surface solvation ability and its hydrophobicity. Indeed, $\mathrm{CsH}$ was more retained than CsA under reversed phase HPLC conditions [18].

\subsection{Effect of Column Temperature}

In SFC of small organic molecules (e.g., MW < 900), column temperature generally has minor to moderate effect on retention time [19] [20]. In most cases, the retention time increases with increased temperature, mainly due to decreased fluid density and elution strength. We observed similar retention time-temperature relationship for the five Cyclosporin analogs. From $0^{\circ} \mathrm{C}$ to $80^{\circ} \mathrm{C}$, the retention times were shifted from $9 \sim 12$ minute range to $12 \sim 15$ minute range.

The temperature effect on selectivity (separation factor) was reported to be of little significance [21]. Generally selectivity decreases slightly with increased column temperature. It was proposed that the interaction between analyte molecule and SFC stationary phase may result in temporary formation of an analyte-stationary phase complex [22]. The stability of this complex was reduced with increased temperature, which would subsequently reduce selectivity between multiple analytes as observed in their experiments. West et al. reported a similar selectivity trend for most of the small molecule analytes, but it was also observed that in some cases the selectivity improved with increased temperature [23]. The authors attributed the latter unusual temperature behavior to high level of desolvation of stationary phase and thus enhanced analyte-stationary phase interaction at high temperature. In terms of peptides, literature data in SFC column temperature effect are very limited. Thurbide et al. studied the temperature effect on SFC separation of multiple linear pentadecapeptides and also observed reduced selectivity as well as broadened peak shape with increased column temperature [24].

In our study of Cyclosporin analogs, we observed that with increased column temperature, selectivity remained almost unchanged. However peak widths were significantly reduced, which suggested enhanced column efficiency, contrasting to the trend that Thurbide observed in the separation of linear peptides [24]. As resolution depends on retention, selectivity and column efficiency, the resolution of the five Cyclosporin analogs improved significantly with increased temperature (Figure 4). At lower temperature as $0^{\circ} \mathrm{C} \sim 10^{\circ} \mathrm{C}$, peaks were very broad with poor separation. At $50^{\circ} \mathrm{C} \mathrm{C}$, baseline resolution was obtained for all the five peaks. The peak shape and resolution continued to improve up to $80^{\circ} \mathrm{C}$.

A similar peak broadening was reported in analysis of Cyclosporin A using reversed phase HPLC on a C18 column [25]. The peak shapes were improved by raising column temperature to $70^{\circ} \mathrm{C}-80^{\circ} \mathrm{C}$. In our case, all the Cyclosporin analogs showed broader peaks at lower temperature, similar to the trend observed in the reversed phase HPLC study [25]. One factor for this trend is the increased viscosity and density of the $\mathrm{CO}_{2}$ mobile phase, especially at temperature below the critical point of $31^{\circ} \mathrm{C}$. Another factor for the broadened peaks might be re- 

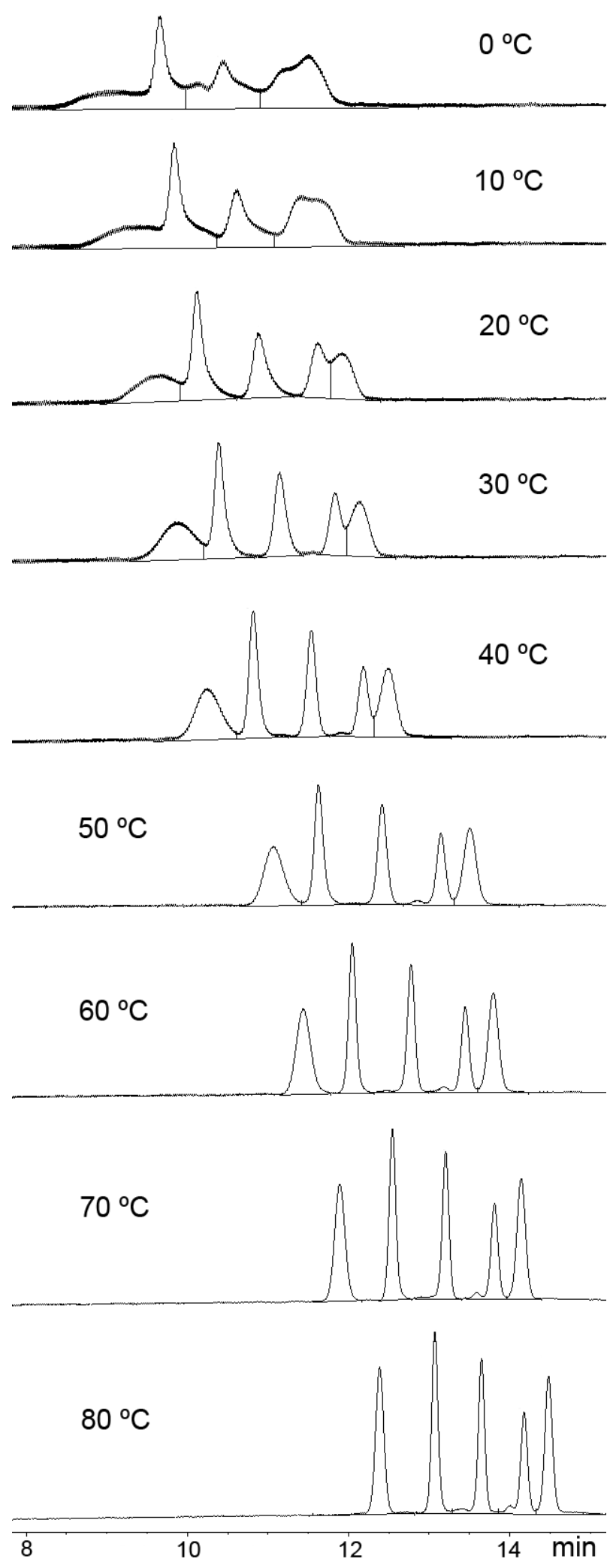

Figure 4. Temperature effect on SFC chromatograms of Cyclosporin analogs. Bare silica column, mobile phase: $\mathrm{CO}_{2}$ modified with $\mathrm{EtOH}$ at 5\% - 30\% gradient, $2 \mathrm{~mL} / \mathrm{min}, 150$ bar. Peak elution order: $\mathrm{H}, \mathrm{D}, \mathrm{A}, \mathrm{B}, \mathrm{C}$. 
lated to peptide's conformational change. Thermodynamically at low temperature peptide molecules are locked at many conformations with local energy minima due to energy barriers that could not be overcome. At elevated temperature, the peptide molecules possess enough energy to pass the barriers, and may change to those conformations with global low energy. Kinetically at high temperature the rates of interconversion between various conformers increase, resulting in sharper peaks [26]. Among the five analogs studied, the biggest temperature effect on peak width was observed with Cyclosporin $\mathrm{H}$. From $0^{\circ} \mathrm{C}$ to $80^{\circ} \mathrm{C}$, the peak width of Cyclosporin $\mathrm{H}$ was improved from $0.70 \mathrm{~min}$ to $0.12 \mathrm{~min}$, while the peak width for Cyclosporin $\mathrm{D}$ (the 2nd peak) was improved in a less degree, from $0.16 \mathrm{~min}$ to $0.09 \mathrm{~min}$. The extremely broadened peak shape of Cyclosporin $\mathrm{H}$ at low temperature may reflect broad conformational variations with its highly convoluted three-dimensional structure due to the presence of a unique D-N-methylvaline [17].

\subsection{Effect of Back Pressure}

SFC back pressure has moderate effect on analyte's retention time [19] [21]. Increased back pressure resulted in reduced retention time. Back pressure generally has little or no effect on selectivity [27] [28], except some isolated cases where back pressure variations were reported to generate large changes in small molecule's selectivity and resolution [29]. Brunelli reported that the magnitude of pressure effect might be related to analyte's polarity and mobile phase strength [30]. Interestingly, our study on Cyclosporin analogs showed that while retention times decreased with increased back pressure, selectivity of the Cyclosporin analogs were noticeable improved when back pressure was increased from 100 bar to 300 bar (Figure 5). Combining the factors discussed above, the best separation of the five Cyclosporin analogs was obtained with the SFC conditions of $80^{\circ} \mathrm{C}$ column temperature and 300 bar back pressure using EtOH as mobile phase modifier on a silica column.

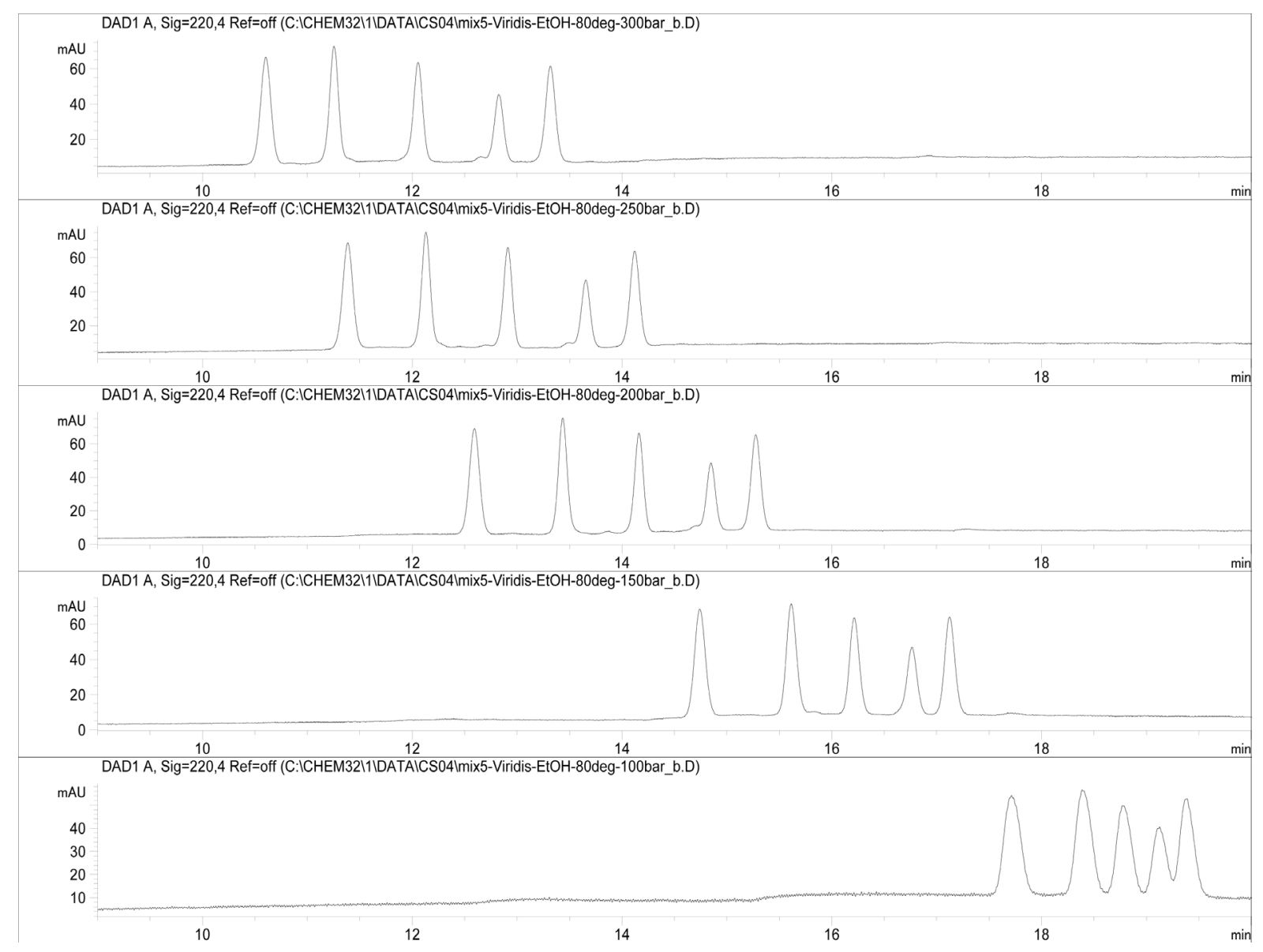

Figure 5. Back pressure effect on SFC chromatograms of Cyclosporin analogs. Silica column, mobile phase: $\mathrm{CO}_{2}$ modified with $\mathrm{EtOH}$ at $5 \%-30 \%$ gradient, $2 \mathrm{~mL} / \mathrm{min}, 80^{\circ} \mathrm{C}$. From bottom: 100, 150, 200, 250, 300 bar. 


\subsection{Effect of Mobile Phase Additives}

Use of common additives such as formic acid or diethyl amine in alcoholic mobile phase modifiers produced little separation changes since the Cyclosporin molecules are nearly neutral. Due to the immiscibility of water and carbon dioxide, water must be used together with alcohol as mobile phase modifier. Petal et al. reported that presence of $0.5 \% \sim 5 \%$ water in alcoholic modifiers significantly improved peak shape and resolution of linear peptides on bare silica column [12]. Our results on the effect of water-containing modifiers were mixed. It was observed that addition of water in mobile phase greatly increased the retention times, broadened the peaks, and changed the selectivities. Using EtOH/ $\mathrm{H}_{2} \mathrm{O}$ 97:3 as mobile phase modifier, the selectivities between Cyclosporin $\mathrm{A}, \mathrm{B}$, and $\mathrm{C}$ were improved while the selectivities between Cyclosporin $\mathrm{H}$ and $\mathrm{D}$ were decreased and the two analogs were coeluted as a single peak.

\section{Conclusion}

Due to structural similarity, separation of multiple Cyclosporin analogs usually involved two or more chromatographic steps. In this study, a rapid Supercritical Fluid Chromatography method to separate five naturally occurring Cyclosporin analogs in single injection has been demonstrated. A bare silica stationary phase was found to be effective to resolve the five analogs with base line separation using ethanol modified carbon dioxide as mobile phase. The elution order followed cLogP prediction as expected with Normal Phase Chromatography mechanism for all the analogs except Cyclosporin H. Column temperature had significant effect on peak shape and resolution of the five analogs, which might involve cyclic peptide's conformational change. Back pressure also played a big role in selectivity. The best separation was achieved with column temperature at $80^{\circ} \mathrm{C}$ and back pressure of 300 bar. The separation of the five Cyclosporine analogs under the optimized SFC conditions has been performed multiple times in our lab with excellent reproducibility. Further work is underway to apply this efficient SFC method to separate synthetic cyclic peptides to facilitate drug discovery process.

\section{References}

[1] Guarracino, D. (2015) Wheel of Fortune-Cyclic Peptides Hit the Mimetic Jackpot: Current Syntheses, Uses and Roles for Cyclic Peptide Mimetics. Current Chemical Biology, 9, 36-52. http://dx.doi.org/10.2174/2212796809666150911201950

[2] Vorherr, T. (2015) Modifying Peptides to Enhance Permeability. Future Medicinal Chemistry, 7, 1009-1021. http://dx.doi.org/10.4155/fmc.15.43

[3] Ahlbach, C.L., Lexa, K.W., Bockus, A.T., Chen, V., Crews, P., Jacobson, M.P. and Lokey, R.S. (2015) Macrocycles in New Drug Discovery. Future Medicinal Chemistry, 7, 2121-2130. http://dx.doi.org/10.4155/fmc.15.78

[4] Watson, G.M., Gunzburg, M.J., Ambaye, N.D., Lucas, W.H., Traore, D.A., Kulkarni, K., Cergol, K.M., Payne, R.J., Panjikar, S. and Pero, S.C. (2015) Cyclic Peptides Incorporating Phosphotyrosine Mimetics as Potent and Specific Inhibitors of the Grb7 Breast Cancer Target. Journal of Medicinal Chemistry, 58, 7707-7718. http://dx.doi.org/10.1021/acs.jmedchem.5b00609

[5] Rashad, A.A., Kalyana S., Ramalingam V., Aneja, R., Duffy, C. and Chaiken, I. (2015) Macrocyclic Envelope Glycoprotein Antagonists That Irreversibly Inactivate HIV-1 before Host Cell Encounter. Journal of Medicinal Chemistry, 58, 7603-7608. http://dx.doi.org/10.1021/acs.jmedchem.5b00935

[6] Cai, M., Marelli, U.K., Bao, J., Beck, J.G., Opperer, F., Rechenmacher, F., McLeod, K.R., Zingsheim, M.R., Doedens, L. and Kessler, H.(2015) Systematic Backbone Conformational Constraints on a Cyclic Melanotropin Ligand Leads to Highly Selective Ligands for Multiple Melanocortin Receptors. Journal of Medicinal Chemistry, 58, 6359-6367. http://dx.doi.org/10.1021/acs.jmedchem.5b00102

[7] Dreyfuss, M., Härri, H., Hofmann, H., Kobel, H., Pache, W. and Tscherter, H. (1976) Cyclosporin A and C New metabolites from Trichoderma polysporum. European Journal of Applied Microbiology, 3, 125-133. http://dx.doi.org/10.1007/BF00928431

[8] Ahn, E.Y., Shrestha, A., Nguyen, H.H., Nguyen, L.H., Yoon, Y.J. and Park, J.W. (2014) Structural Characterization of Cyclosporin A, C and Microbial Bio-Transformed Cyclosporin A Analog AM6 Using HPLC-ESI-Ion Trap-Mass Spectrometry. Talanta, 123, 89-94. http://dx.doi.org/10.1016/j.talanta.2014.01.067

[9] Carruthers, S.G., Freeman, D.J., Koegler, J.C., Howson, W., Keown, P.A., Laupacis, A. and Stiller, C.R. (1983) Cyclosporin A and C. Clinical Chemistry, 29, 180-183.

[10] Lensmeyer, G.L., Wiebe, D.A. and Carlson, I.H. (1987) Identification and Analysis of Nine Metabolites of Cyclospo- 
rine in Whole Blood by Liquid Chromatography. Clinical Chemistry, 33, 1841-1850.

[11] Thurbide, K.B. and Zhang, J. (2005) Separation of Linear Gramicidins Using Carbon Dioxide-Containing Mobile Phases. Analytical and Bioanalytical Chemistry, 382, 1227-1233. http://dx.doi.org/10.1007/s00216-005-3270-9

[12] Patel, M.A., Riley, F., Ashraf, K.M., and Taylor, L.T. (2012) Supercritical Fluid Chromatographic Resolution of Water Soluble Isomeric Carboxyl/Amine Terminated Peptides Facilitated via Mobile Phase Water and Ion Pair Formation. Journal of Chromatography A, 1233, 85-90. http://dx.doi.org/10.1016/j.chroma.2012.02.024

[13] Zheng, J., Pinkston, J.D., Zoutendam, P.H. and Taylor L.T. (2006) Feasibility of Supercritical Fluid Chromatography/Mass Spectrometry of Polypeptides with Up to 40-Mers. Analytical Chemistry, 78, 1535-1545. http://dx.doi.org/10.1021/ac052025s

[14] Kalinoski, H.T., Wright, B.W. and Smith, R.D. (1988) Chemical Ionization Mass Spectra of High Molecular Weight, Biologically Active Compounds Produced Following Supercritical Fluid Chromatography. Biomedical \& Environmental Mass Spectrometry, 15, 239-242. http://dx.doi.org/10.1002/bms.1200150409

[15] Aaltonen, O., Alkio, M., Lundell, J., Ruohonen, S., Parvinen, L. and Suoninen, V. (1988) Purification of Pharmaceuticals and Nutraceutical Compounds by Sub and Supercritical Chromatography and Extraction. Pharmaceutical Technology Europe, 10, A42-A54.

[16] Viswanadhan, V.N., Ghose, A.K., Revankar, G.R. and Robins, R.K. (1989) Atomic Physicochemical Parameters for Three Dimensional Structure Directed Quantitative Structure-Activity Relationships. Journal of Chemical Information and Computational Science, 29, 163-172. http://dx.doi.org/10.1021/ci00063a006

[17] Potter, B., Palmer, R.A., Withnall, R. and Chowdhry, B. (2003) Two New Cyclosporin Folds Observed in the Structures of the Immunosuppressant Cyclosporin G and the Formyl Peptide Receptor Antagonist Cyclosporin H at Ultra-High Resolution. Organic \& Biomolecular Chemistry, 1, 1466-1474. http://dx.doi.org/10.1039/b210086j

[18] Zheng, W. (2008) Separation of Cyclosporins and Other Antibiotics by HSCCC. Journal of Chromatographic Science, 47, 354-358. http://dx.doi.org/10.1093/chromsci/47.5.354

[19] Enmark, M., Asberg, D., Samuelsson, J. and Fornstedt, T. (2014) The Effect of Temperature Pressure and Co-Solvent on a Chiral Supercritical Fluid Chromatography Separation. Chromatography Today, 8, 14-17.

[20] Ibhfiez, E., Tabera, J., Herraiz, M. and Reglero, G. (1994) Effect of Temperature and Density on the Performance of Micropacked Columns in Supercritical Fluid Chromatography. Journal of Chromatography A, 667, 249-255. http://dx.doi.org/10.1016/0021-9673(94)89074-9

[21] Caldwell, J. and Webster, G.K. (2014) Super Critical Fluid Chromatography. CRC Press, Taylor \& Francis Group LLC, Boca Raton.

[22] Gasparrini, F., Misiti, D. and Villani, C. (1990) Direct Resolution of Racemic Compounds on Chiral Microbore Columns by Sub- and Supercritical Fluid Chromatography, Journal of High Resolution Chromatography, 13, $182-184$. http://dx.doi.org/10.1002/jhrc.1240130309

[23] West, C., Bouet, A, Routier, S. and Lesellier, E. (2012) Effects of Mobile Phase Composition and Temperature on the Supercritical Fluid Chromatography Enantioseparation of Chiral Fluoro-Oxoindole-Type Compounds with Chlorinated Polysaccharide Stationary Phases. Journal of Chromatography A, 1269, 325-335.

http://dx.doi.org/10.1016/j.chroma.2012.09.078

[24] Thurbide, K. and Zhang, J. (2005) Separation of Linear Gramicidins Using Carbon Dioxide-Containing Mobile Phases. Analytical and Bioanalytical Chemistry, 382, 1227-1233. http://dx.doi.org/10.1007/s00216-005-3270-9

[25] Bowers, L.D. and Mathews, S.E. (1985) Investigation of the Mechanism of Peak Broadening Observed in the HighPerformance Liquid Chromatographic Analysis of Cyclosporine. Journal of Chromatography A, 333, 231-238. http://dx.doi.org/10.1016/S0021-9673(01)87348-9

[26] Augustijns, P.F., Brown, S.C., Willard, D.H., Consler, T.G., Annaert, P.P, Hendren, R.W. and Bradshaw, T.P. (2000) Hydration Changes Implicated in the Remarkable Temperature-Dependent Membrane Permeation of Cyclosporin A. Biochemistry, 39, 7621-7630. http://dx.doi.org/10.1021/bi9929709

[27] Wang, C. and Zhang, Y. (2013) Effects of Column Back Pressure on Supercritical Fluid Chromatography Separations of Enantiomers Using Binary Mobile Phases on 10 Chiral Stationary Phases. Journal of Chromatography A, 1281, 127-134. http://dx.doi.org/10.1016/j.chroma.2013.01.050

[28] Wang, C., Tymiak, A.A. and Zhang, Y. (2014) Optimization and Simulation of Tandem Column Supercritical Fluid Chromatography Separations Using Column Back Pressure as a Unique Parameter. Analytical Chemistry, 86, 40334040. http://dx.doi.org/10.1021/ac500530n

[29] Lou, X., Janssen, H.G., Snijders, H. and Cramers, C.A. (1996) Pressure Drop Effects on Selectivity and Resolution in Packed Column Supercritical Fluid Chromatography. Journal of High Resolution Chromatography, 19, 449-456.

http://dx.doi.org/10.1002/jhrc.1240190806 
[30] Brunelli, C., Zhao, Y., Brown, M.H. and Sandra, P. (2008) Development of a Supercritical Fluid Chromatography High-Resolution Separation Method Suitable for Pharmaceuticals Using Cyanopropyl Silica. Journal of Chromatography A, 1185, 263-272. http://dx.doi.org/10.1016/j.chroma.2008.01.050 